\title{
Identifikasi Rhodamin B dalam Lipstik dengan Metode KLT dan Spektrofotometri UV-VIS
}

\author{
Hurip Budi Riyanti ${ }^{1 *}$, Sutyasningsih ${ }^{1}$, Anggun Wisnu Sarsongko ${ }^{1}$ \\ ${ }^{1}$ Fakultas Farmasi dan Sains, Universitas Muhammadiyah Prof. DR. Hamka, Jakarta \\ *Email Korespondensi: huripbudiriyanti@uhamka.ac.id
}

doi: $10.29405 /$ j.bes/68-73121338

Received: 28 April 2018 | Accepted:29 Mei 2018 | Published: 05 Juni 2018

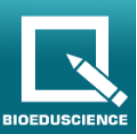

\begin{abstract}
Abstrak
Tujuan: Keberadaan lipstik di pasaran harus terus mendapatkan pengawasan terhadap penggunaan bahanbahan berbahaya, khususnya pewarna yang dilarang digunakan dalam kosmetik. Rhodamin B merupakan zat warna kimia sintetik yang biasa digunakan untuk mewarnai berbagai macam tekstil.Namun Rhodamin B sering disalahgunakan untuk mewarnai berbagai macam kosmetik. Penelitian ini bertujuan untuk mengetahui keberadaan pewarna berbahaya Rhodamin B pada sediaan lipstik yang beredar di pasar Jakarta Timur. Metode: Survei pasar yang diperoleh 11 jenis lipstik dengan merk yang berbeda. Teknik samplingnya menggunakan teknik Judgement Sampling, sampling dilakukan berdasarkan lokasi pengambilan sampel yang mutlak ditentukan sendiri oleh peneliti. Pada uji pendahuluan dilakukan dengan menggunakan Kromatografi Lapis Tipis (KLT) yaitu sampel yang diperoleh dipreparasi untuk menghilangkan zat pengganggu, kemudian dilarutkan dengan menggunakan metanol, lalu ditotolkan pada kromatografi lapis tipis. Tahap selanjutnya yaitu sampel positif dari uji pendahuluan diekstraksi dengan menggunakan eter, kemudian diidentifikasi dengan menggunakan Spektrofotometri UV-Vis untuk uji konfirmasi. Hasil: Hasil identifikasi dengan menggunakan Kromatografi Lapis Tipis dan Spektrofotometri UV-Vis diperoleh data bahwa dari 11 sampel, terdapat 1 sampel lipstik yang positif mengandung Rhodamin B (9,09\% dari 11 sampel). Kesimpulan: 11 sampel lipstik yang beredar di empat pasar di wilayah Jakarta Timur yang diidentifikasi terdapat 1 sampel (9,090\% dari 11 sampel ) yang mengandung zat warna Rhodamin B.
\end{abstract}

Kata kunci: Rhodamin B; Lipstik; Kromatografi Lapis Tipis (KLT); Spektrofotometri UV-Vis

\begin{abstract}
Background: The existence of lipstick in the market must be controlled on the usage of dangerous substances especially color which is forbidden for cosmetic. Rhodamin B is a synthetical chemical color which is usually used to color textile. However rhodamin is often misused to color many kinds of cosmetics. The research objective is to find existence of the dangerous color substance in lipstick in the market of east Jakarta. Methods: Survey conducted in the markets finds 11 kinds of lipstick with different brands. Sampling technique used is judgment sampling which is conducted based on sampling location defined by the researcher. Preliminary test is conducted using thin layer chromatography, received sample is prepared to eliminate contaminant, then it is diluted by methanol, then it is drop on thin layer chromatography. After that the sample is extracted by using ether, then it is identified by using spectrophotometer UV -Vis to confirm. Results: Results of identification using thin layer chromatography and UV-Vis Spectrophotometry showed that from 11 samples, there was 1 positive lipstick sample containing Rhodamin B ( 9.09\% from 11 samples). Conclusions: 11 lipstick samples circulating in four markets in East Jakarta identified 1 sample (9,090\% from 11 samples) containing Rhodamin B.
\end{abstract}

Keyword: Rhodamin B; Liptick; Thin layer Chromatography, Spectrofotometry UV-Vis

(C) 2018 Bioeduscience. all rights reserved 


\section{PENDAHULUAN}

Lipstik merupakan sediaan kosmetik yang terbuat dari lilin, pigmen atau pewarna dan minyak. Lipstik sudah menjadi kebutuhan bagi wanita pada zaman modern ini sebagai pewarna bibir. Banyak diantara wanita merasa kurang tampil percaya diri di depan umum tanpa menggunakan pewarna bibir. Kebutuhan lipstik yang terus meningkat, seiring dengan beredarnya produk lipstik baru baik dalam negeri maupun merek global yang terus mengikuti kebutuhan konsumennya. Lipstik dewasa ini dikemas dengan iklan dan kemasan yang sangat menarik disamping pilihan warnanya yang semakin banyak (Wartaka M, 2016).

Zat warna mempunyai peran dalam pewarnaan lipstik sehingga lipstik yang dihasilkan memberikan warna dan penampilan yang sangat menarik sehingga konsumen tertarik untuk menggunakannya.

Sesuai Keputusan Kepala Badan Pengawas Obat dan Makanan No. HK.00.05.4.1475 pasal 3 tanggal 5 Mei 2003 tentang kosmetik, beberapa zat warna dilarang penggunaanya dalam sediaan kosmetik termasuk lipstik, antara lain Rhodamin B (Ka Badan POM 2003). Rhodamin B adalah salah satu pewarna sintetik yang umumnya digunakan sebagai pewarna kertas dan tekstil. Penggunaan Rhodamin B sebagai pewarna kosmetika dapat menimbulkan iritasi pada kulit, iritasi pada mata dan bersifat karsinogenik. Mengingat bahaya tersebut, penggunaan pewarna Rhodamin B dapat merugikan dan membahayakan kesehatan masyarakat (Agus G, 2009 ). Rhodamin B dapat mengiritasi saluran pernafasan dan juga bersifat karsinogenik atau memacu pertumbuhan kanker jika digunakan terus menerus. Sifat karsinogenik tersebut disebabkan oleh unsurN ${ }^{+}$(Nitronium) dan $\mathrm{Cl}^{-}$ (Klorin) yang terkandung dalam rhodamin $\mathrm{B}$ yang bersifat sangat reaktiff dan berbahaya. Penumpukan Rhodamin B dalam hati akan menyebabkan gangguan fungsi hati dan berupa kanker hati dan tumor hati. (Afriyeni, et al., 2016).

Untuk mengetahui kemungkin digunakan pewarna rhodamin B dalam sediaan lipstik yang beredar di pasaran dilakukan penelitian untuk mengidentifikasi pewarna Rhodamin B dalam sediaan lipstik yang beredar di pasaran. Sasaran lipstik yaitu yang berwarna merah mencolok dengan harga murah yang diminati oleh konsumen menengah ke bawah yang beredar di pasar di wilayah Jakarta Timur.

\section{MATERI DAN METODE}

\section{Alat dan Bahan}

Timbangan analitik, alat- alat gelas, penangas air, spatel, pipet tetes, sudip, corong pemisah, kertas saring, kromatografi lapis tipis, spektrofotometer UV-Vis. Lipstik, asam klorida, metanol, eter, baku pembanding (BP) pewarna Rhodamin B.

\section{Prosedur Peneliitan}

\section{Persiapan}

Kriteria sampel lipstik curah yang akan di sampling pada penelitian ini adalah:

a) Lipstik yang beredar di pasar di Wilayah Jakarta Timur

b) Berwarna merah mencolok

c) Harganya murah kisaran Rp.5000 Rp. 6000

Cara mendapatkan sampel yaitu dilakukan dengan cara survei semua lipstik curah yang beredar dari keempat pasar besar di wilayah Jakarta Timur. Pasar tersebut meliputi Pasar Kramat Jati, Pasar Jatinegara, Pasar Cakung dan Pasar Klender Lama, kemudian didapatkan 11 jenis lipstik dengan merk yang berbeda. Lokasi pengambilan sampel 
ditentukan dengan menggunakan teknik Judgement sampling. Pasar besar tersebut merupakan pusat peredaran kosmetik di wilayah Jakarta Timur, selanjutnya dilakukan pengujian terhadap kesebelas sampel tersebut.

a. Larutan uji

Sejumlah lebih kurang $500 \mathrm{mg}$ sampel ditambahkan 4 tetes asam klorida $4 \mathrm{M}$, ditambah $5 \mathrm{ml}$ metanol, lalu dilelehkan pada penangas air, kemudian ditambahkan metanol sampai $10 \mathrm{ml}$ dan disaring dengan kertas saring (A).

b. Larutan Baku Pembanding

$50 \mathrm{mg}$ pewarna Rhodamin B baku pembanding dilarutkan dalam $100 \mathrm{ml}$ metanol (B).

c. Campuran larutan uji dan baku pembanding

Dibuat campuran antara larutan (A) dan (B) dengan jumlah volume yang sama untuk menghasilkan larutan (C).

\section{Pelaksanaan dan Pengamatan}

a. Cara identifikasi dengan Kromatografi lapis tipis

Larutan A, B dan C masing-masing ditotolkan secara terpisah dan dilakukan kromatografi lapis tipis sebagai berikut:

- Fase diam : silika gel G

- Fase gerak :

i. Etil asetat $-\mathrm{n}-$ butanol - amonia (20 : $55: 25)$

ii. Etil asetat - metanol - amonia (15:6 : 3)

iii. $\mathrm{n}$ - propanol - amonia $(90: 10)$

- Penjenuhan : dengan kertas saring

- Volume penotolan : Larutan A, B dan C masing-masing $10 \mu \mathrm{L}$ Jarak rambat $12 \mathrm{~cm}$

- Penampak bercak

i. Tanpa penampak bercak, bercak berwarna merah

ii. dengan UV 254, bercak berfluoresensi kuning. b. Cara identifikasi dengan Spektrofotometri $\mathrm{UV}-\mathrm{Vis}$

1) Larutan uji

Menimbang lebih kurang $5 \mathrm{~g}$ sampel dimasukkan ke dalam Beaker glass, lalu ditambahkan $30 \mathrm{ml}$ larutan natrium hidroksida $2 \%$, diaduk dan dipanaskan di atas penangas air hingga mencair. Cairan dimasukkan ke dalam corong pisah $100 \mathrm{ml}$, lalu ditambahkan $30 \mathrm{ml}$ eter, dikocok selama 3 menit dan didiamkan hingga memisah. Kemudian fase air dibuang, fase eter dicuci dua kali dengan $20 \mathrm{ml}$ larutan natrium hidroksida $0,5 \%$. Lalu cucian dibuang, fase eter ditambah $10 \mathrm{ml}$ asam klorida $0,1 \mathrm{~N}$ dan dikocok, fase asam ditampung (A).

2) Larutan baku pembanding

Menimbang lebih kurang 50mg baku pembanding Rhodamin B dilarutkan dalam $250 \mathrm{ml}$ metanol. Lalu sejumlah lebih kurang $1 \mathrm{ml}$ larutan ini ditambahkan dengan $25 \mathrm{ml}$ asam klorida $0,1 \mathrm{~N}(\mathrm{~B})$.

3) Campuran larutan uji dan baku pembanding

Dibuat campuran antara larutan (A) dan (B) dengan jumlah volume yang sama untuk menghasilkan larutan $(\mathrm{C})$.

4) Identifikasi

Serapan maksimum larutan A, B dan C masing-masing diukur pada panjang gelombang lebih kurang $558 \mathrm{~nm}$ menggunakan asam klorida $0,1 \mathrm{~N}$ sebagai blanko.

\section{Metode Kromatografi Lapis Tipis (KLT):}

Membandingkan harga Rf antara baku rhodamin $\mathrm{B}$ dengan sampel menggunakan 3 eluen yang berbeda. Bila harga Rf antara baku rhodamin B dengan sampel hampir sama, maka sampel mengandung rhodamian B ( hasil positif)

\section{Metode Spektrofotometri :}

Untuk mengkonfirmasi hasil positif yang diperoleh dari metode KLT diukur serapannya 
dan dilihat panjang gelombang maksimum serta profil spektrogramnya menggunakan spektrofotometer. Hasil positif menunjukkan panjang gelombang dan spektrumnya sama serta ada serapannya.

\section{HASIL}

Pada penelitian ini diambil sampel lipstik curah yang beredar di wilayah Jakarta Timur yang banyak diminati oleh masyarakat ekonomi menengah ke bawah. Jakarta Timur mempunyai empat pasar besar yaitu Pasar Kramat Jati, Pasar Jatinegara, Pasar Cakung dan Pasar Klender Lama. Sampel diperoleh dengan menggunakan metode judgement sampling, yaitu dengan cara mencari data semua sampel lipstik curah yang beredar di Pasar Kramat Jati, Pasar Jatinegara, Pasar Cakung dan Pasar Klender Lama. Kemudian didapatkan sebelas sampel lipstik curah dengan merk yang berbeda dari keempat pasar tersebut.

Sampel lipstik yang diperoleh kemudian dilakukan pengujian dengan menggunakan kromatografi lapis tipis sebagai uji pendahuluan. Sampel yang positif dari hasil uji pendahuluan kemudian dilakukan pengujian selanjutnya yaitu dengan menggunakan Spektrofotometri UV- Vis sebagai uji konfirmasi. Uji konfirmasi bertujuan untuk memastikan sampel positif mengandung Rhodamin B. Sebelum dilakukan Spektrofotometri, sampel di ekstraksi terlebih dahulu untuk menghilangkan lemaknya dan zat pengganggu, sehingga di dapatkan zat warna penyusun sampel tersebut.

Data yang diperoleh dari pengujian dengan menggunakan Kromatografi lapis tipis adalah sebagai berikut:

Tabel 1. Data harga Rf sampel dalam 3 macam eluen. No Harga Rf
Eluen A $\quad$ B $\quad$ C

$\begin{array}{llll}\text { (BP.Rhodamin B) } & 0,9 & 0,91 & 0,9\end{array}$

1. Sampel 1

2. Sampel 2

$0 \quad 0 \quad 0$

3. Sampel 3

4. Sampel 4

5. Sampel 5

6. Sampel 6

7. Sampel 7

8. Sampel 8

9. Sampel 9

10. Sampel 10

11. Sampel 11

Keterangan:

Eluen $\mathrm{A}=$ Etil asetat $: \mathrm{n}$ - butanol : amonia (20:55:25)

Eluen $\mathrm{B}=$ Etila asetat $:$ metanol : amonia $(15: 6: 3)$

Eluen $\mathrm{C}=\mathrm{n}-$ propanol : amonia $(90: 10)$

Hasil dari kromatografi lapis tipis di atas di dapatkan 1 sampel yang positif mengandung Rhodamin B selanjutnya dilakukan pengujian dengan menggunakan Spektrofotomerti UV-Vis.

Tabel 2.Data Panjang gelombang $(\lambda)$ maksimum

\begin{tabular}{llll}
\hline No & Keterangan & $\boldsymbol{\lambda}$ maksimum & Absorban \\
\hline 1 & BP & 558 & 0,7579 \\
& Rhodamin B & & \\
2 & Sampel 4 & 557 & 0,3120 \\
\hline
\end{tabular}

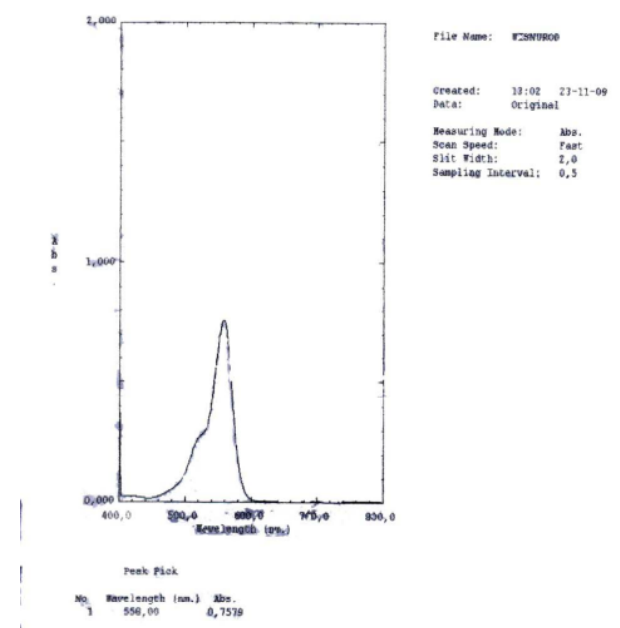


Gambar1. Spektrum zat warna pembanding Rhodamin B dalam $\mathrm{HCl} 0,1 \mathrm{~N}$

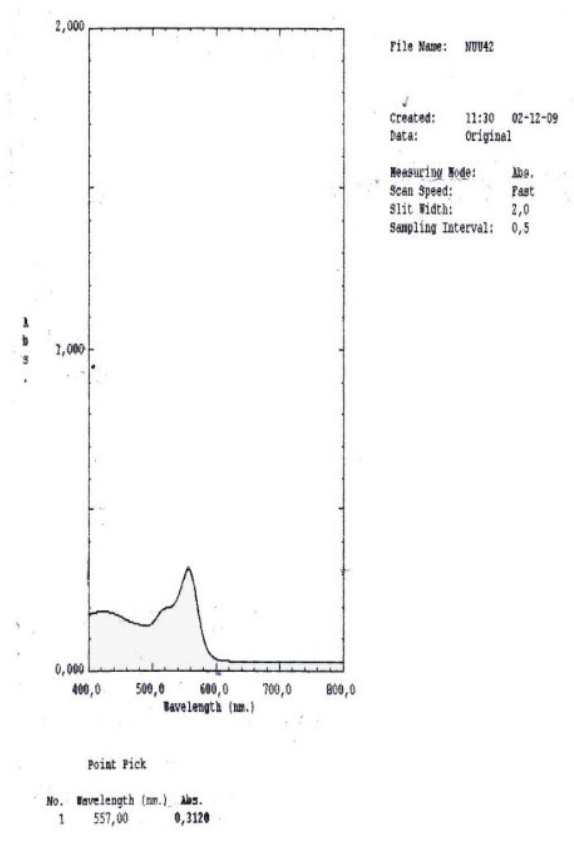

Gambar 2. Spektrum Sampel dengan pelarut $\mathrm{HCl} 0,1 \mathrm{~N}$ yang di identifikasi mengandung Rhodamin B.

\section{PEMBAHASAN}

Cara pengambilan Sampel yaitu dengan cara mensurvei semua lipstik yang beredar di wilayah Jakarta Timur, antara lain, Pasar Kramat Jati, Pasar Jatinegara, Pasar Cakung dan Pasar Klender Lama, kemudian didapatkan 11 jenis lipstik dengan merk yang berbeda. Lokasi pengambilan sampel tersebut menggunakan tehnik Judgement sampling. Judgement sampling yaitu lokasi pengambilan sampel mutlak ditentukan sendiri oleh peneliti. Sampel lipstik yang digunakan yaitu lipstik curah dengan kisaran harga Rp5000 - Rp6000.
Proses untuk memisahkan zat warna yang terkandung dalam sampel yaitu dengan cara melarutkan sampel dengan menggunakan metanol. Zat warna yang terlarut dalam metanol kemudian diidentifikasi dengan menggunakan kromatografi lapis tipis dan identifikasi selanjutnya menggunakan spektrofotometer UVVis untuk uji konfirmasi. Pada penelitian ini digunakan kromatografi lapis tipis untuk uji pendahuluan, selanjutnya dikonfirmasi dengan menggunakan metode spektrofotometri untuk memastikan hasil positif benar rhodamin B.

Sampel dipreparasi terlebih dahulu untuk menghilangkan zat pengganggu yang terkandung di dalamnya sehingga memudahkan proses ekstraksi zat pewarna. Tahap selanjutnya adalah melarutkan sampel dengan metanol. Setelah dilakukan identifikasi dengan meggunakan kromatografi lapis tipis dari 11 sampel didapatkan 1 sampel yang mengandung pewarna Rhodamin B.

Terdapat sampel yang positif mengandung rhodamin $\mathrm{B}$ baik menggunakan metode KLT maupun spektrofotometri, artinya masih ada oknum yang menyalahgunakan penggunaan rhodamin B sebagai pewarna listik. Hal tersebut akan membahayakan pengguna karena pemakaian yang terus menerus bisa mengakibatkan iritasi kulit, bahkan kanker dan tumor . menggunakan spektrofotometri UV-Vis untuk membuktikan bahwa sampel tersebut postif mengandung Rhodamin B.

\section{KESIMPULAN}

Dari sejumlah 11 sampel lipstik yang beredar di empat pasar di wilayah Jakarta Timur yang diidentifikasi terdapat 1 sampel $(9,090 \%$ dari 11 sampel ) yang mengandung zat warna Rhodamin B. 


\section{DAFTAR PUSTAKA}

Wartaka, M. 20016. Analysis of the Consumers Preferences of Lipstick Product and its Realtionship with the segmentation of the Lipstick Poduct . Journal The Management Journal of Binaniaga Vol 01.N0.02.page 7

Anonim. 2003. Keputusan Kepala Badan Pengawas Obat dan Makanan Republik Indonesia No. HK.00.05.4.1475.Tentang Kosmetik. Badan Pengawas Obat dan Makanan RI. Hal 5, 24.

Agus, G. Analisa bahan pewarna berbahaya pada sediaan kosmetik di wilayah kecamatan Buleleng Kabupaten Buleleng. 2009. www. Freewebs.com, Dilihat, 30 April 2009. Jam 11.15.

Ardiani, V. 2009. Penyakit Kulit Anatomi dan Jenis Penyakitnya. Dalam: Seminar UHAMKA, Penyakit Kulit dan Pengobatannya.UHAMKA, Jakarta.

Rieger, M.M. 2000. Hary's Cosmeticology, Chemical Publishing, co.inc, New York. Hal 314-315.

Anonim. 2009. Wikipedial Rhodamine B. www.brown.edu, Dilihat 13 April 2009. Jam 19.17 .

Anonim. 2004. LIPI/ Berita-artikel/ Rhodamine. www.kimi@net.mht, Dilihat 30 Maret 2009. Jam 10.02 .

Anonim. 2007. Keputusan Direktur Jenderal Pengawasan Obat dan Makanan No. KH.00.01.432.6081 Tentang Public Warning/ Peringatan tentang Kosmetika Mengandung Bahan Berbahaya dan Zat Warna Yang Dilarang. Jakarta: Departemen Kesehatan.

Departemen Kesehatan Republik Indonesia. 1995. Farmakope Indonesia Edisi IV. Departemen Kesehatan RI. Jakarta. Hal1002.

Anonim. 2009. Artikel / kimia indonesia / kromatografi. www.chem-is-try.org, Dilihat 10 Juli 2009. Jam 14.30.

Clarke, E.G.C.1984. Isolation and Identification of Drugs. London The Pharmaceutical Press. Hal. 164.

Anonim. 1975. Farmakope Indonesia Edisi III. Departemen Kesehatan RI. Jakarta. Hal 772.

Anonim. 2008. Modul Pelatihan Spektrofotometri $U V$-VIS. Badan Pengawas Obat dan Makanan RI, Jakarta. Hal. 1, 3-4.

Anonim. 2001. Identifikasi Pewarna Rhodamin B (CI 45170)Dalam Lipstik. Badan Pengawas Obat dan Makanan RI,Jakarta. Hal. 164-165.

Anonim. 1995. Identifikasi Pewarna Rhodamin B Merah K-10 (CI 45170) Dalam Sediaan
Kosmetik. Badan Pengawas Obat dan Makanan RI, Jakarta. Hal. 149-150.

Susilo, S., \& Suciati., R. (2016). Studies of Morphological and Secondary Metabolites Variaty of Mosses (Bryophyta) in Cibodas, West Java. International Journal of Advanced Research, 4(12), 1397-1402. doi: 10.21474/IJAR01/2536

Touchstone JC, Dobbins MF. 1983. Practice of The Layer Chromatography. 2nd edition. New York ,John Willey \& sons Inc,. Hal 303-310.

Helmice Afriyeni, Nila Wise Utari, 2016, Identifikasi zat warna Rhodamin B pada Lipstik yang berwarna merah yang beredar di Pasar raya Padang, Jurnal farmasi Higea, Vol 8, No. 1, 2016 hal $59-64$. 